\title{
Multiphasic kinetics can be an artifact of the assumption of saturable kinetics for microorganisms
}

\author{
Bruce E. Logan, Robert C. Fleury \\ Department of Chemical and Environmental Engineering, University of Arizona, Tucson, Arizona 85721, USA
}

\begin{abstract}
Much of the evidence for the application of Michaelis-Menten kinetics to bacterial suspensions is derived from Wright-Hobbie plots of radionuclide uptake and incorporation rates in the presence of naturally occurring concentrations of substrates. It is shown that the same data used to support saturation models can also be fitted by a diffusion-based transport equation. Mixed, pure and natural assemblages of microorganisms were used to study glucose uptake and thymidine and leucine incorporation. Multiphasic kinetics for glucose uptake by mixed cultures was observed when data were plotted on a Wright-Hobbie plot $(K+S$ values of 2.7 .37 and $3500 \mu M)$, but the diffusion model fit data with a single set of coefficients over a 6 orders of magnitude range in glucose concentrations. It is suggested that diffusive transport into the cell is dominant at the relatively high thymidine and leucine concentrations used in bacterial production studies, and that non-saturable diffusive transport contributes to widely varying bacterial conversion factors.
\end{abstract}

KEY WORDS: Diffusion Kinetics Leucine Thymidine - Uptake

\section{INTRODUCTION}

It is generally assumed that uptake of dissolved molecules by bacteria in aquatic systems obeys Michaelis-Menten kinetics (Wetzel 1983). According to this model, uptake ( $v$ ) can be related to substrate concentration $(S)$ by

$$
v=\frac{V_{\max } S}{K+S}
$$

where $V_{\text {max }}$ is the maximum (saturated) uptake rate, and $K$ is substrate concentration at $V_{\max } / 2$. Several linearization techniques, such as Linweaver-Burke, Hanes and Hofstee plots, can be used to calculate values of $V_{\max }$ and $K$ (Bailey \& Ollis 1977). Unfortunately, $K$ cannot be determined easily for bacteria in natural systems since it is only possible to measure the concentrations of a limited numbers of chemicals, such as some amino acids (Lindroth \& Mopper 1979) and monosaccharides (Mopper et al. 1992).

Wright \& Hobbie (1966) developed a method of estimating the upper limit of $K$ based on amending water samples with radiolabeled compounds. They found relatively high $K+S$ values of 0.002 to $0.003 \mathrm{mg}$ $\mathrm{l}^{-1}$ for glucose and 0.006 to $0.015 \mathrm{mg} \mathrm{l}^{-1}$ for acetate in Lake Erken (Sweden) plankton. Although their method (reviewed below) produced an estimate of the sum of $K+S$, neither $K$ nor $S$ could be determined independently using their technique. It is now generally thought that $K+S$ is similar in magnitude to $S$ in natural systems, or that $K<S$ (Fuhrman \& Ferguson 1986). However, it has been found that the uptake of some compounds, such as thymidine, is not saturable even when $S \gg K$ (Hollibaugh 1988, Bell 1990, Kaplan et al. 1992). Furthermore, estimates of $K$ vary by orders of magnitude based on measured concentrations of $S$. For example, a range in $K$ of -7 to $26 \mathrm{nM}$ is necessary to account for alanine uptake by natural bacterial assemblages from the Long Island Sound (USA) at alanine concentrations of 4.2 to $14.5 \mathrm{nM}$ (Fuhrman \& Ferguson 1986), while a range in $K$ of 2.0 to $157 \mathrm{nM}$ was reported for alanine in an earlier study (Jørgensen \& Sondergaard 1984).

The Wright-Hobbie method continues to be an important method for aquatic microbiologists for at 
least 2 reasons. First, it is used as the basis of several tests used to estimate bacterial production. In order to estimate bacterial production by either incorporation into macromolecular protein or DNA fractions, for example by using using radiolabeled leucine and thymidine, it is necessary to 'swamp' out concentrations of naturally occurring compounds (Kirchman et al. 1986). The assumption of these methods is that at sufficiently high concentrations of unlabeled $(U)$ and radiolabeled $(A)$ compounds, uptake is saturated and independent of concentration and de novo synthesis is repressed. However, many kinetic plots do not demonstrate saturation kinetics (Hollibaugh 1988, Bell 1990). Wright \& Hobbie (1966) only assumed Michaelis-Menten kinetics at 'low' substrate concentrations and stated that diffusive transport would dominate at 'higher' concentrations. The absence of saturation kinetics in bacterial incorporation studies should produce uptake rates that are a function of both the amount of added substrate and the amount of naturally occurring substrate. It is not surprising, therefore, that recent work indicates that the magnitude of thymidine conversion factors used to estimate bacterial production are positively correlated with the total added substrate concentration (Bell 1990).

A second major reason Wright-Hobbie plots are important is that these plots have been used as the basis for concluding that bacteria possess multiple transport systems. Using natural assemblages of marine bacteria, Azam \& Hodson (1981) estimated 6 different values of $K$ for glucose uptake based on Wright-Hobbie plots containing only 2 points per plot (their Fig. 5). In a later study, Nissen et al. (1984) demonstrated that multiple $K$ values were not a result of separate microorganisms in the assemblage, by obtaining 4 ranges of $K$ values using a single oligotrophic marine bacterium. Multiphasic kinetics were also used by Fuhrman \& Ferguson (1986) as an explanation for the wide range in $K$ suggested by alanine uptake studies.

It is argued here that multiphasic kinetics are not necessary to explain glucose uptake kinetics by pure and mixed cultures. We propose an alternative explanation for non-saturable uptake that is based on a physical model of chemical diffusion across a permeable membrane. By assuming that uptake is proportional to substrate concentration (and cannot be saturated), it will be shown that Wright-Hobbie and other plots based on saturation kinetics can produce apparent multiphasic kinetics. The application of Wright-Hobbie methods to non-saturable conditions produces multiple estimates of $K+S$ that are a function of the concentrations of added substrates used in the experiments.

\section{METHODS}

Theoretical development. The Wright-Hobbie formulation was based on modifying Eq. (1) to include concentrations of naturally occurring $(S)$, added radiolabeled $(A)$ and unlabeled $(U)$ substrate, or

$$
v=\frac{V_{\max }(S+U+A)}{K+S+U+A}
$$

By inverting Eq. (2), we obtain the linear equation

$$
\frac{S+U+A}{V}=\frac{K+S}{V_{\max }}+\frac{U+A}{V_{\max }}
$$

If only the rate of radiolabel incorporation ( $\left.V_{\text {meas }}\right)$ is measured, then the actual and measured rates are related by

$$
V_{\text {meas }}=\frac{V A}{S+U+A}
$$

Substituting Eq. (4) into Eq. (3) and rearranging, yields

$$
\frac{A}{V_{\text {meas }}}=\frac{K+S}{V_{\max }}+\frac{U+A}{V_{\max }}
$$

The term $A / V_{\text {meas }}$ is identical to the term ' $\mathrm{C} \mu \mathrm{t} / \mathrm{C}$ ' derived by Wright \& Hobbie (1966). If $U=S=0$, Eq. (5) is identical to a Hanes plot of kinetic data.

The alternative model to Eq. (2) that is proposed here, which is not based on saturation kinetics, is

$$
V=k(S+U+A)^{b}
$$

The basis of this model is diffusion across a permeable membrane with rapid reaction (removal or utilization) assumed to occur within the cell. The permeability constant $k$ is expected to be a function of the charge of the compound, the solution ionic strength and the composition and thickness of a membrane (Bailey \& Ollis 1977). The constant $b$ should theoretically be unity for diffusion through an inorganic membrane, but the magnitude of $b$ may vary for microbial uptake as a function of several factors discussed below.

The diffusion equation can be rearranged to produce an equation analogous to Eq. (5). Proceeding as above, the diffusive rate equation is inverted and Eq. (4) is substituted into Eq. (6) to yield

$$
\frac{A}{V_{\text {meas }}}=\frac{1}{k}(S+U+A)^{(1-b)}
$$

This equation can be linearized by taking the log of both sides to produce

$$
\ln \left(\frac{A}{V_{\text {meas }}}\right)=\ln \left(\frac{1}{k}\right)+(1-b) \ln (S+U+A)
$$

A plot of $\ln \left(A / V_{\text {meas }}\right)$ versus $\ln (S+U+A)$ yields the values of the rate constant $k$ and $b$ from the $y$-intercept of $\ln (1 / k)$ and slope of $(1-b)$. 
For natural systems, the applicability of Eq. (8) is limited by the fact that $S$ is unknown. However, if concentrations of substrate are used so that $(U+A) \gg S$, then Eq. (7) can be simplified to

$$
\frac{A}{V_{\text {meas }}}=\frac{1}{k}(U+A)^{(1-b)} \text { for }(U+A) \gg S
$$

Experiments. Bacteria: Radiolabeled uptake experiments were conducted using 3 different types of samples: a mixed culture prepared from a commercially available inoculum, a pure culture and a natural assemblage. The mixed culture was prepared from a dehydrated inoculum to ensure that the comparable communities of microorganisms were used in experiments that spanned several months. Each inoculum (Polylseed, Polybac Corp., Bethlehem, PA, USA) contained $100 \mathrm{mg}$ of a microbial culture and growth stimulants in a capsule. To rehydrate, 1 capsule was opened and poured into $500 \mathrm{ml}$ of aerated, nutrient-buffered water for $60 \mathrm{~min}$. This solution was used within $6 \mathrm{~h}$.

Mixed cultures were grown to late stationary growth (indicated by cell absorbance at $600 \mathrm{~nm}$ ) on $0.5 \mathrm{~g} \mathrm{l}^{-1}$ of a 50:50 mixture of glucose : glutamic acid and mineral salts buffer (MSB) in a 21 flask stirred with a magnetic stir bar. The culture was washed by centrifugation at $1110 \times g$ for $5 \mathrm{~min}$ and resuspended in fresh medium. The culture was serially filtered immediately before use through 10 and $5 \mu \mathrm{m}$ polycarbonate membranes (Poretics Corp.) at $<250 \mathrm{~mm} \mathrm{Hg}$ to remove any flocs that had formed during centrifugation. MSB consisted of (per liter of distilled water): $0.57 \mathrm{~g} \mathrm{NH}_{4} \mathrm{NO}_{3}, 0.5 \mathrm{~g}$ $\mathrm{KH}_{2} \mathrm{PO}_{4}, \quad 1.00 \mathrm{~g} \mathrm{~K} \mathrm{KPO}_{4}, 0.20 \mathrm{~g} \mathrm{MgSO}_{4}, 0.04 \mathrm{mg}$ $\mathrm{FeCl}_{3} \cdot \mathrm{H}_{2} \mathrm{O}$, and $0.02 \mathrm{mg}$ vitamin $\mathrm{B}_{12}$.

For pure culture experiments we used Pseudomonas fluorescens P17 provided by C. Gerba, Dept of Microbiology and Immunology, University of Arizona, USA. P17 was chosen because it readily grows at low substrate concentrations (it was isolated from a water distribution system in The Netherlands), was adapted to glucose as a growth substrate, and is a Gram-negative rod. The culture was maintained on R2A agar (Difco) plates stored at $4^{\circ} \mathrm{C}$ and transferred to sterile liquid media in $20 \mathrm{ml}$ test tubes overnight prior to each experiment. Tubes were then used to inoculate a $2 \mathrm{l}$ fermentor (Virtis, Omniculture) filled to $1 \mathrm{l}$, stirred at $300 \mathrm{rpm}$, supplied with $31 \mathrm{~min}^{-1}$ of air, and operated at room temperature $\left(23^{\circ} \mathrm{C}\right)$. The buffer used for $\mathrm{P} 17$ was (per liter of distilled water): $4.10 \mathrm{~g}$ MOPS [3-(nmorpholino)-propanesulfonic acid] buffer, $1.00 \mathrm{~g} \mathrm{NH}_{4} \mathrm{Cl}_{\text {, }}$ $0.02 \mathrm{~g} \mathrm{~K}_{2} \mathrm{HPO}_{4}, 0.05 \mathrm{~g} \mathrm{MgSO}_{4} \cdot \mathrm{H}_{2} \mathrm{O}, 0.08 \mathrm{~g} \mathrm{CaCl}_{2}$, $0.04 \mathrm{mg} \mathrm{FeCl}$, and $0.48 \mathrm{~g} \mathrm{NaOH}_{\text {; the }} \mathrm{pH}$ was adjusted to 7.2 using strong acid or base.

Seawater samples were obtained off the coast of California, USA $\left(33^{\circ} 55^{\prime} \mathrm{N}, 120^{\circ} 34^{\prime} \mathrm{W}\right)$ on April 18 , 1990. Samples from the surface water $(5 \mathrm{~m})$ were brought to room temperature and filtered through a $1.0 \mu \mathrm{m}$ polycarbonate membrane filter (Poretics) at $<100 \mathrm{~mm} \mathrm{Hg}$ prior to each experiment. All cells were counted using standard acridine orange epifluorescence methods (Hobbie et al. 1977) at $1000 \times$.

Uptake and incorporation: Uptake of $\left[{ }^{3} \mathrm{H}\right]$ glucose and $\left.l^{3} \mathrm{H}\right]$ leucine and incorporation rates of $\left[^{3} \mathrm{H}\right]$ thymidine and $\left[{ }^{3} \mathrm{H}\right]$ leucine and into their respective macromolecular fractions were measured in separate experiments using $5 \mathrm{ml}$ of pure, mixed or seawater cultures (in duplicate). In uptake experiments, $\left[{ }^{3} \mathrm{H}\right]$ glucose $\left(1-2-{ }^{3} \mathrm{H}\right.$, $35 \mathrm{Ci} \mathrm{mmol}{ }^{-1}, \mathrm{ICN}$, Costa Mesa, CA) and non-radiolabeled glucose, or $\left[{ }^{3} \mathrm{H}\right]$ leucine $\left(108 \mathrm{Ci} \mathrm{mmol}{ }^{-1}\right.$; ICN) were added to $20 \mathrm{ml}$ test tubes followed by $5 \mathrm{ml}$ of a cell suspension. Each tube was mixed on a vortexer for 3 to $5 \mathrm{~s}$, incubated at room temperature for 10 to $60 \mathrm{~min}$, killed with $0.5 \mathrm{ml}$ of $37 \%$ formalin, vortexed again, and the sample filtered through a $0.45 \mu \mathrm{m}$ (Gelman) filter at $200 \mathrm{~mm} \mathrm{Hg}$ in a 10 bay filter box (Hoefer Scientific) fitted with stainless steel funnels and teflon valves. Each filter was rinsed twice with $2 \mathrm{ml}$ of $3.7 \%$ formaldehyde followed by 2 rinses of $5 \mathrm{ml}$ of buffered water, and counted (Beckman Model 3801 scintillation counter). Adsorption blanks were run using $0.5 \mathrm{ml}$ of $37 \%$ formaldehyde.

$\left[{ }^{3} \mathrm{H}\right]$ Thymidine $\left(54 \mathrm{Ci} \mathrm{mmol}{ }^{-1}\right.$; ICN) incorporation was measured using standard procedures (Fuhrman \& Azam 1982). Samples were prepared as above except $50 \%$ TCA was added to kill the microorganisms, and soluble thymidine was extracted from cells by cooling in an ice water bath for $15 \mathrm{~min}$ prior to filtration. Cells were rinsed twice with $2 \mathrm{ml}$ of ice cold TCA $(5 \%)$ followed by 2 rinses of $0.5 \mathrm{ml}$ of $70 \%$ ethanol. Filters were air dried and counted.

$\left.{ }^{3} \mathrm{H}\right]$ Leucine $\left(60,79\right.$ or $108 \mathrm{Ci} \mathrm{mmol}^{-1}$; ICN) incorporation into the protein fraction was measured using procedures developed by Kirchman et al. (1985). Samples were prepared as described for thymidine incorporation except that a 15 min hot water extraction step $\left(80^{\circ} \mathrm{C}\right)$ was used.

\section{RESULTS}

\section{Theoretical}

The effect of non-saturable kinetics on a WrightHobbie plot of $A / V_{\text {meas }}$ versus $U+A$ can be calculated using Eq. (9). If uptake is always first order with added substrate, then $b=1$ and all data fall on a straight horizontal line (Fig. 1A). Wright \& Hobbie (1966) recognized this result and presented a horizontal line indicating diffusion in one of their figures (their Fig. 7), although they did not further explore the effect of diffusion on observed uptake. 



Fig. 1. Effect of different diffusion model (Eq. 9) constants on appearance of rate data in a Wright-Hobbie plot: (A) different values of $k$ and $b$ can produce non-linear responses in this type of plot; (B) naturally occurring substrate $(S=5)$ would tend to flatten out data near the $y$-axis

There are several reasons why $b$ may be less than unity (as discussed later), but values of $b<1$ produce non-linear responses on Wright-Hobbie plots. As $b$ decreases slightly, lines become nearly vertical with very small values of $U+A$, eventually becoming flat at higher $U+A$ (Fig. 1A). The effect of decreased values of the rate constant $k$ is to lower the overall position of the line

If we assume that Fig. $1 A$ accurately represents uptake or incorporation rates then values of $K+S$ determined from this plot would be highly dependent on the $U+A$ region of the plot used to calculate $K+S$.
Similarly, choosing different $U+A$ values to conduct an experiment would bias the results for different values of $K+S$.

Data in many Wright-Hobbie plots are linear with a positive slope and do not exhibit the curved slopes of the type shown in Fig. 1A that are characteristic of multiphasic kinetics. However, uptake rates produced by the nonsaturated model can also produce straight lines on Wright-Hobbie plots if low concentrations of naturally occurring substrate are present in the sample. If we calculate the true uptake rate based on $S=5$ using Eq. (6), and plot these rates as $A / V_{\text {meas }}$ versus $U+A$ in a Wright-Hobbie plot, we see that the resulting line is nearly straight while the line plotted for the same conditions but with $S=0$ is curved (Fig. 1B). As $S$ increases, the sharp slope near the $y$-axis becomes more linear with higher concentrations of $U+A$. Thus, low concentrations of $S$ have the effect of making the data appear more linear and more like expected data for determination of $K+S$ in a WrightHobbie plot, although only the assumption of unsaturated kinetics was necessary to prepare the figure.

\section{Glucose uptake}

A Wright-Hobbie plot of glucose uptake by the mixed culture (Fig. 2A) demonstrates the apparent multiphasic kinetics observed by others for pure and mixed assemblages of marine bacteria (Azam \& Hodson 1981, Nissen et al. 1984). Over the range of

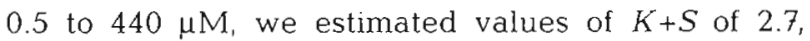
37 and $3500 \mu \mathrm{M}$. However, since cultures were washed prior to measurements, it can be assumed that $S=0$, or $K=K+S$. Kinetic constants were also determined using the unsaturated model (Eq. 9) and plotted on the same Wright-Hobbie plot for comparison. The resulting equation (Fig. 2B) indicates good agreement with the data over the range of glucose concentrations.

Using additional data from a separate experiment, the range of glucose concentrations was expanded and the resulting data analyzed using the unsaturated model. These data have a slope of $0.89\left(\mathrm{r}^{2}=0.996\right)$ and appear highly linear with substrate concentration (Fig. 2C) over 6 orders of magnitude.

Additional experiments using a pure culture produced similar results for glucose uptake. Uptake was highly linear for a range of glucose concentrations spanning 6 orders of magnitude (Fig. 3). The resulting slope was $1.11 \pm 0.01\left(r^{2}=0.9986\right)$.

\section{Thymidine incorporation}

Thymidine incorporation by the mixed culture produced the same apparent multiphasic kinetics when analyzed using a Wright-Hobbie plot. Over a $10^{1}$ to 

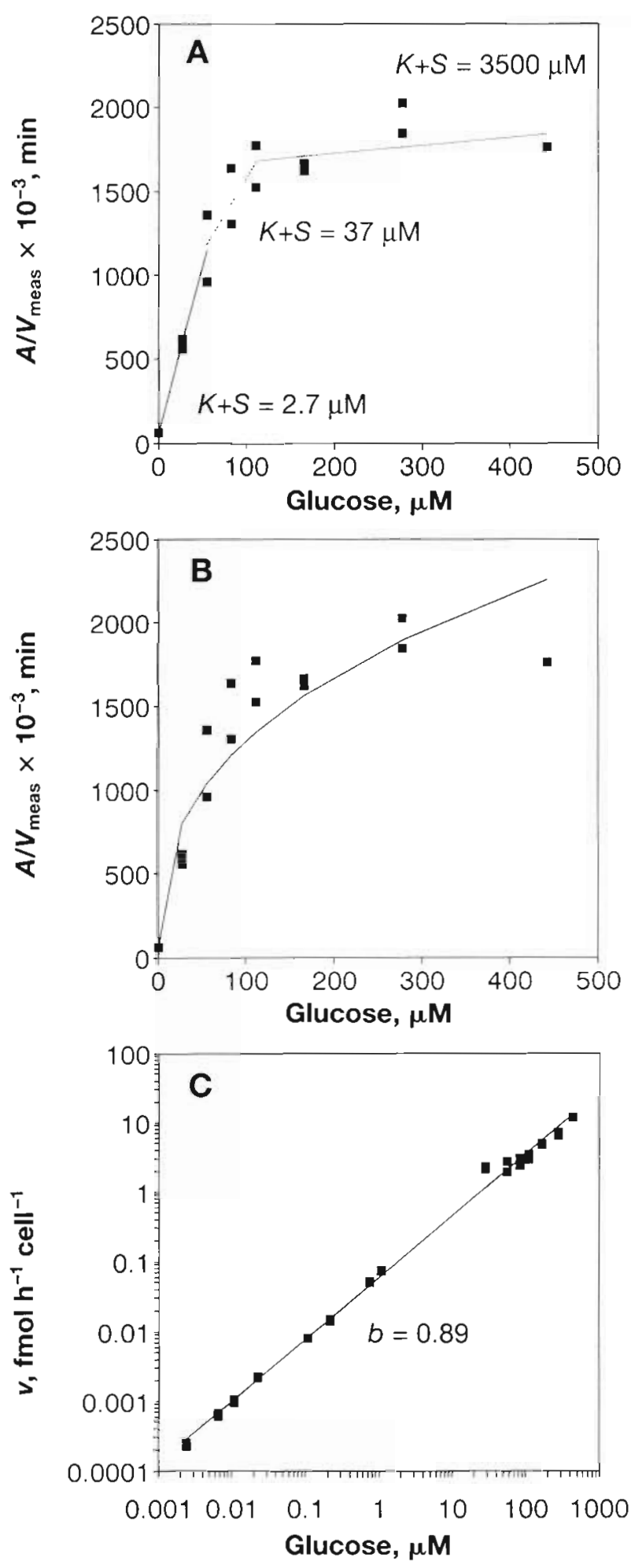

Fig. 2. Glucose uptake by a mixed culture (Polyseed, incubation time $60 \mathrm{~min}$ ): (A) data analyzed according to WrightHobbie plots suggest there are at least 3 different halfsaturation constants; (B) same data as in (A), but fitted with the diffusion model ( $b=0.37, k=17500)$; $(\mathrm{C})$ expanded range of glucose concentrations analyzed with the diffusion model $\left(b=0.89, k=0.06, \mathrm{r}^{2}=0.996\right)$

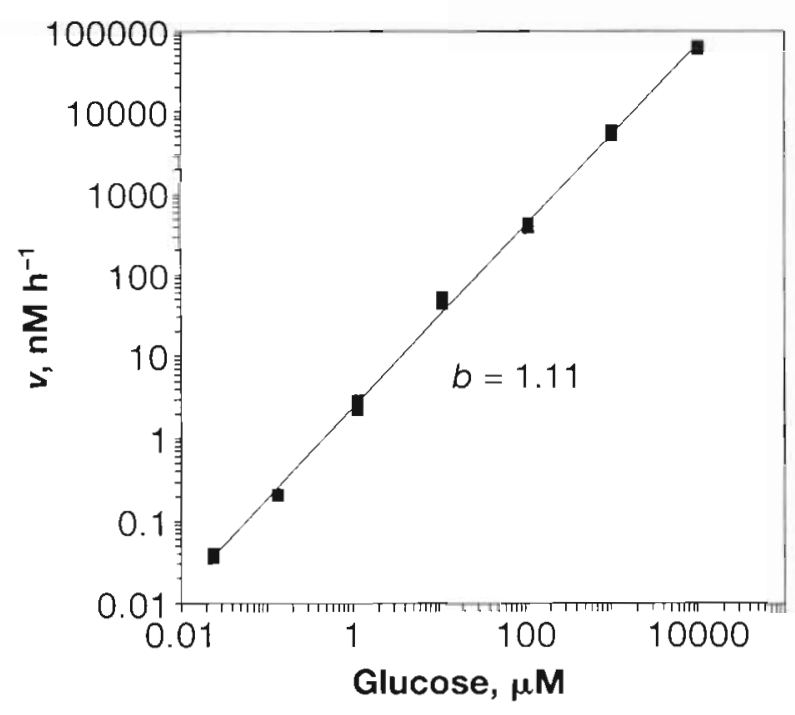

Fig. 3. Glucose uptake by a pure culture (Pseudomonas fluorescens $\mathrm{P} 17$, incubation time $30 \mathrm{~min}, b=1.11, k=2.4, \mathrm{r}^{2}=0.996$ )

$10^{7} \mathrm{nM}$ thymidine concentration range, $K+S$ values were 4, 30 and $660 \mathrm{nM}$ for increasing concentrations of thymidine (Fig. 4A). Analysis of the same data using the unsaturated kinetic model again results in a linear plot with a slope of $0.65\left(r^{2}=0.95\right)$ (Fig. 4B).

When the same experiment was repeated using a pure culture, the slope was nearly unity $(b=0.986$, $r^{2}=0.97$ ) over a concentration range of $10^{-2}$ to $10^{4} \mu \mathrm{M}$ (Fig. 5). This suggests that rates, and therefore the slopes of incorporation versus concentration, are different for mixed assemblages than pure cultures.

\section{Leucine incorporation}

In separate experiments with both mixed and pure cultures, leucine incorporation was not linear over a $10^{-6}$ to $10^{2} \mathrm{mM}$ concentration range (Figs. $6 \& 7$ ). The lines of best fit over the lower concentration ranges $\left(<10^{3} \mathrm{nM}\right)$ produce slopes of 0.94 (mixed culture) and 0.88 (pure culture). The plateaus in uptake between $10^{-3}$ and $10^{-1} \mathrm{mM}$ for the mixed culture (Fig. 6B) and $10^{-2}$ and $10^{1} \mathrm{mM}$ for the pure culture (Fig. 7) suggest some type of saturation kinetics. However, above $10^{1} \mathrm{mM}$, incorporation continued with increasing leucine concentrations and appeared linear.

\section{Leucine uptake}

The value of the half-saturation constant for leucine uptake is generally regarded as being ca $1 \mathrm{nM}$ in marine systems (Kirchman et al. 1986). As a result, leucine incorporation in natural systems is often assumed to be 

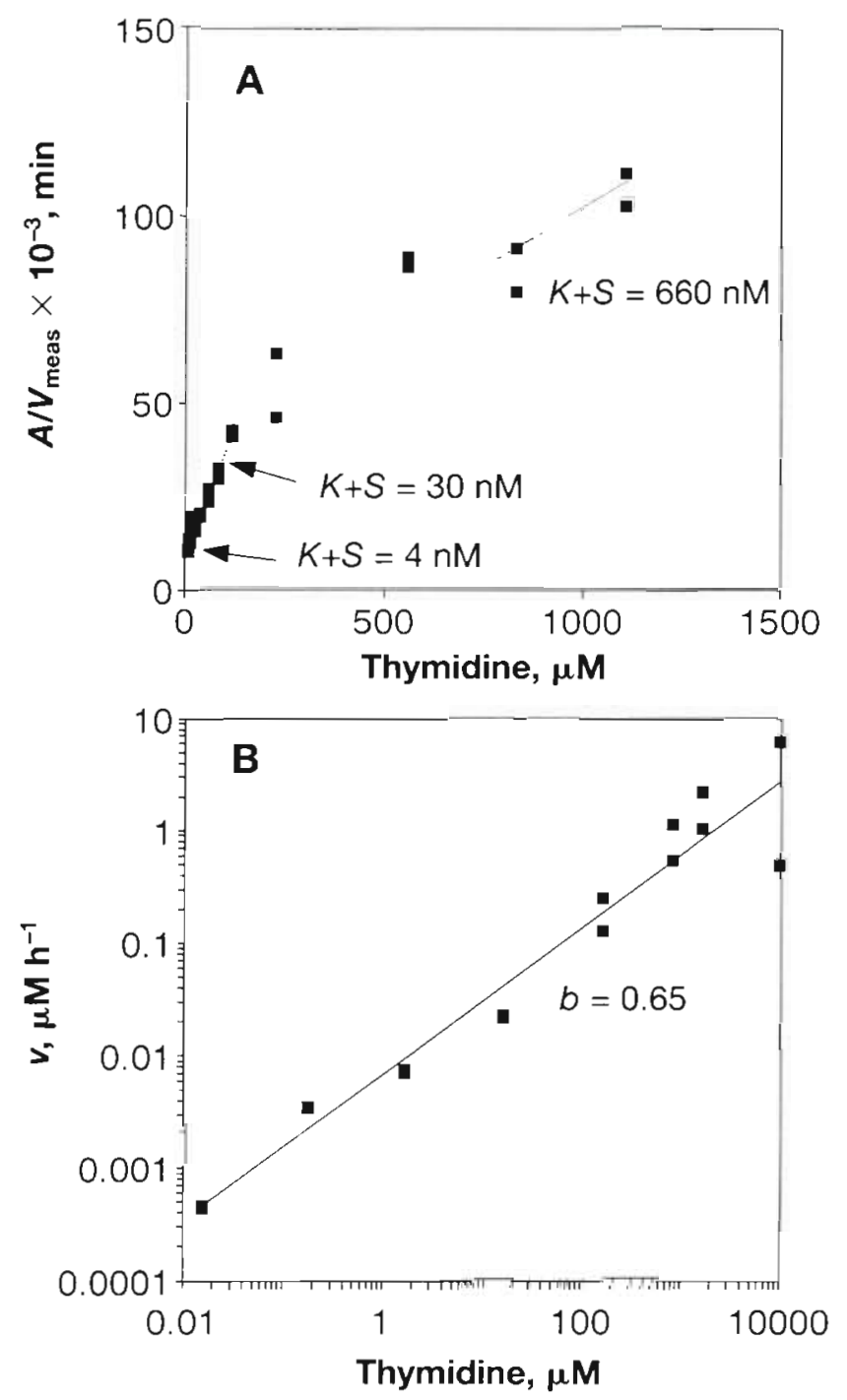

Fig. 4. Thymidine incorporation by a mixed culture (wastewater samples, incubation time $45 \mathrm{~min}$ ): (A) data analyzed according to Wright-Hobbie plots indicates at least 3 different half-saturation constants; (B) same data as in (A), but fitted with the diffusion model $\left(b=0.65, k=0.0068, r^{2}=0.95\right)$

saturated at concentrations greater than $10 \mathrm{nM}$, and a concentration of $30 \mathrm{nM}$ is suggested as sufficient to swamp the concentration of naturally occurring leucine and to saturate uptake enzymes (Simon \& Azam 1989). While it may be possible to swamp out the low concentrations of leucine in many natural systems, we have frequently noticed that leucine kinetics in the 1 to $20 \mathrm{nM}$ range are not saturable. The lack of saturable kinetics is often associated with scattered uptake data in WrightHobbie plots.

Natural bacterial assemblages examined for leucine uptake from the California Bight produced a $K+S$ value of $27 \mathrm{nM}$, but the data were highly scattered producing a low $\mathrm{r}^{2}=0.30$ (Fig. 8A), If the same data are plotted

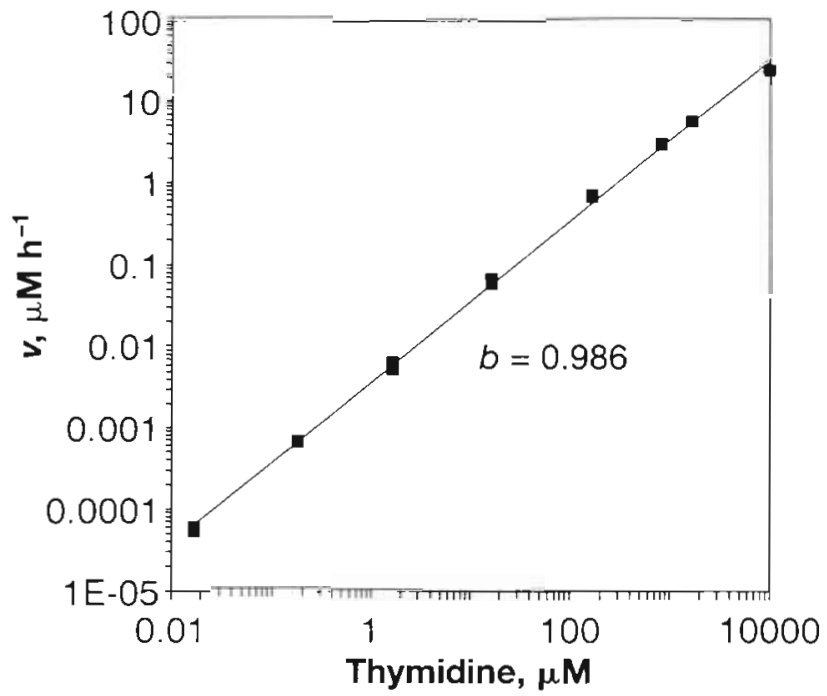

Fig. 5. Thymidine incorporation by a pure culture (Pseudomonas fluorescens P17, incubation time $20 \mathrm{~min}, b=0.986$, $k=0.0035, \mathrm{r}^{2}=0.98$ )

using the non-saturated model, however, uptake is apparently first-order $\left(b=0.95, r^{2}=0.92\right)$ with leucine concentration over the whole substrate range examined $(0.3$ to $21 \mathrm{nM}$ ) (Fig. $8 \mathrm{~B}$ ). The linearity of uptake in the log-log plot results suggests that leucine concentrations were low compared to the concentrations of added substrate and that uptake by this assemblage was not saturated. A comparison of the 2 results with the original data on linear axes (Fig. 8C), assuming $S=0$, does not help resolve which model better represents the data due to the large scatter of the data in this plot.

\section{DISCUSSION}

For both pure and mixed cultures, glucose uptake continued to increase with concentration over a concentration range spanning 6 orders of magnitude (Figs. 2 \& 3). When analyzed using Wright-Hobbie plots, glucose uptake demonstrated the same apparent multiphasic uptake observed by Nissen et al. (1984) for marine microbes. The kinetic constants calculated in Fig. 2 were also within the same range of values identified by Nissen et al. (1984) over 4 different phases or ranges of concentrations (Table 1). However, when the same data were analyzed using the unsaturated model, glucose uptake could be modeled using only a single pair of constants.

Apparent multiphasic kinetics was also observed for thymidine incorporation. However, log-log plots of incorporation versus thymidine concentration were also linear and were consistent with a model based on unsaturated kinetics (Fig. 4). 

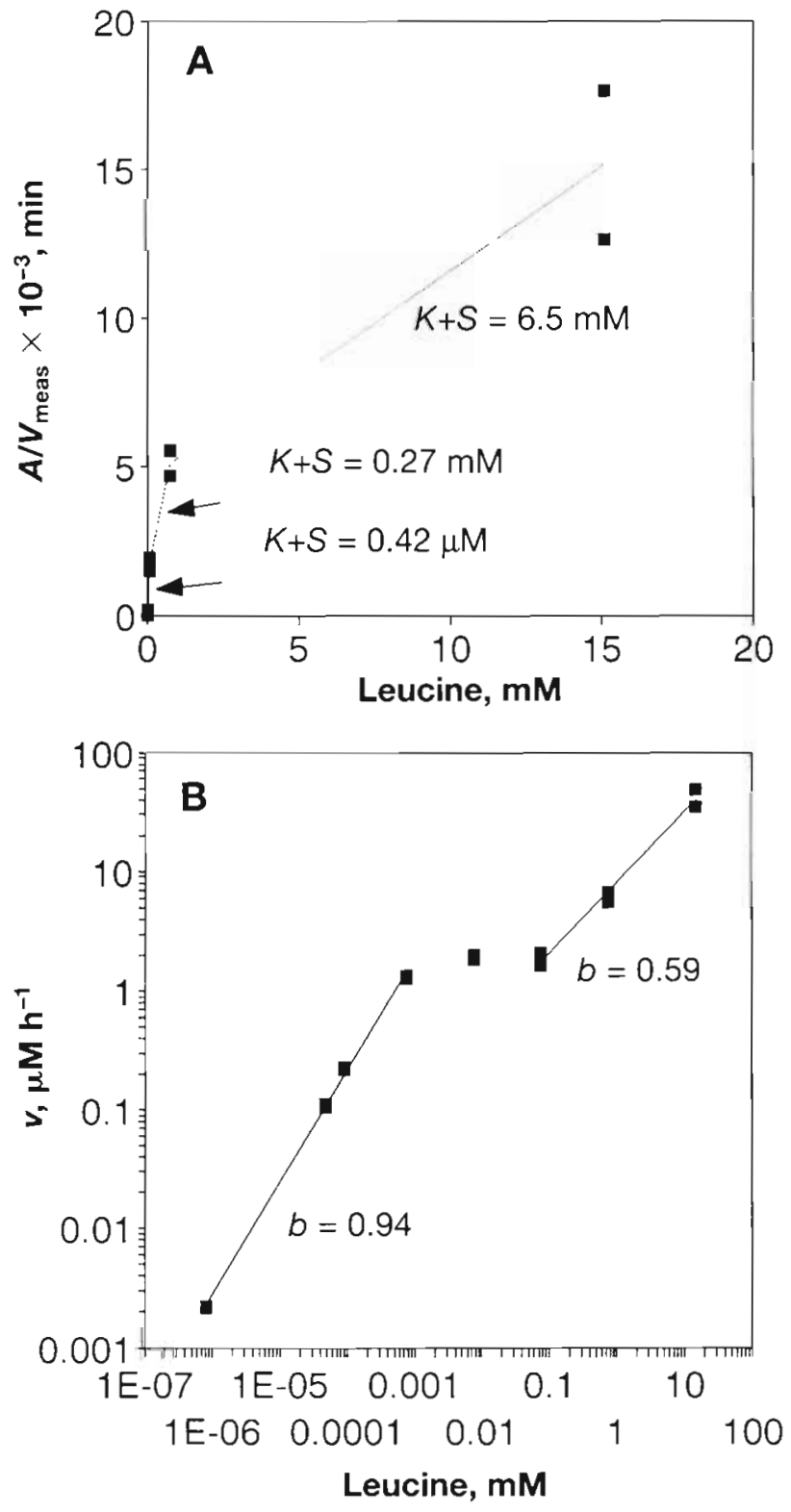

Fig. 6. Leucine incorporation by a mixed culture (Polyseed, incubation time $10 \mathrm{~min}$ ): (A) data analyzed according to WrightHobbie plots; (B) same data in (A) analyzed using the diffusion model indicate 2 regions of linearity on the log-log plot

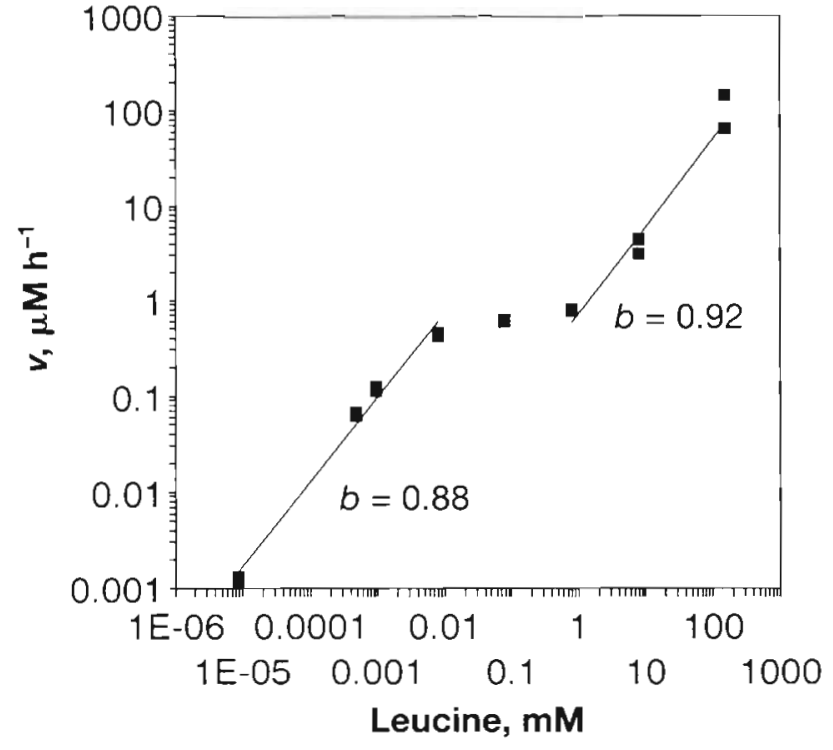

Fig. 7. Leucine incorporation by a pure culture ( $P_{\text {seudomonas }}$ fluorescens P17, incubation time $20 \mathrm{~min}$ ) also shows 2 linear regions of uptake on a $\log -\log$ plot seen for the mixed culture in Fig. 6

In general, the slopes in plots of incorporation or uptake versus concentration were closer to unity for pure than for mixed cultures. There are several reasons that slopes could be less than unity. One reason for slopes less than unity (for all cases) could be preferential uptake by microbes of non-radiolabeled forms of chemicals. In experiments spanning 6 orders of magnitude of compound concentration, it was necessary to use large amounts of non-radiolabeled substrates. The greater permeability or utilization of non-radiolabeled forms would cause an apparent decrease in rates at higher substrate concentrations, yielding lower estimates of both $k$ and $b$ constants in the unsaturated model.

Values of the unsaturated model constant $b$ less than unity for mixed cultures could also result from different membrane permeabilities of different bacterial species, and different thymidine incorporation rates by bacteria growing at different rates in the mixed culture.

Table 1. Half-saturation constants for glucose uptake by bacteria

\begin{tabular}{|c|c|c|c|c|c|}
\hline \multirow{2}{*}{$\begin{array}{l}\text { Type of } \\
\text { bacteria }\end{array}$} & \multirow[b]{2}{*}{ Phase 1} & \multicolumn{3}{|c|}{ Half-saturation constant, $K(\mu \mathrm{M})$} & \multirow[t]{2}{*}{ Source } \\
\hline & & Phase 2 & Phase 3 & Phase 4 & \\
\hline $\begin{array}{l}\text { Mixed culture } \\
\text { (Polyseed) }\end{array}$ & - & 2.7 & 37 & 3500 & This study \\
\hline $\begin{array}{l}\text { Mixed culture } \\
\text { (Polyseed) }\end{array}$ & 3.3 & - & 26 & - & Fleury (1993) \\
\hline $\begin{array}{l}\text { Oligotrophic } \\
\text { marine bacterium }\end{array}$ & $0.04-0.3$ & $1.3-6.7$ & $15-200$ & $2700-3500$ & Nissen et al. (1984) \\
\hline
\end{tabular}



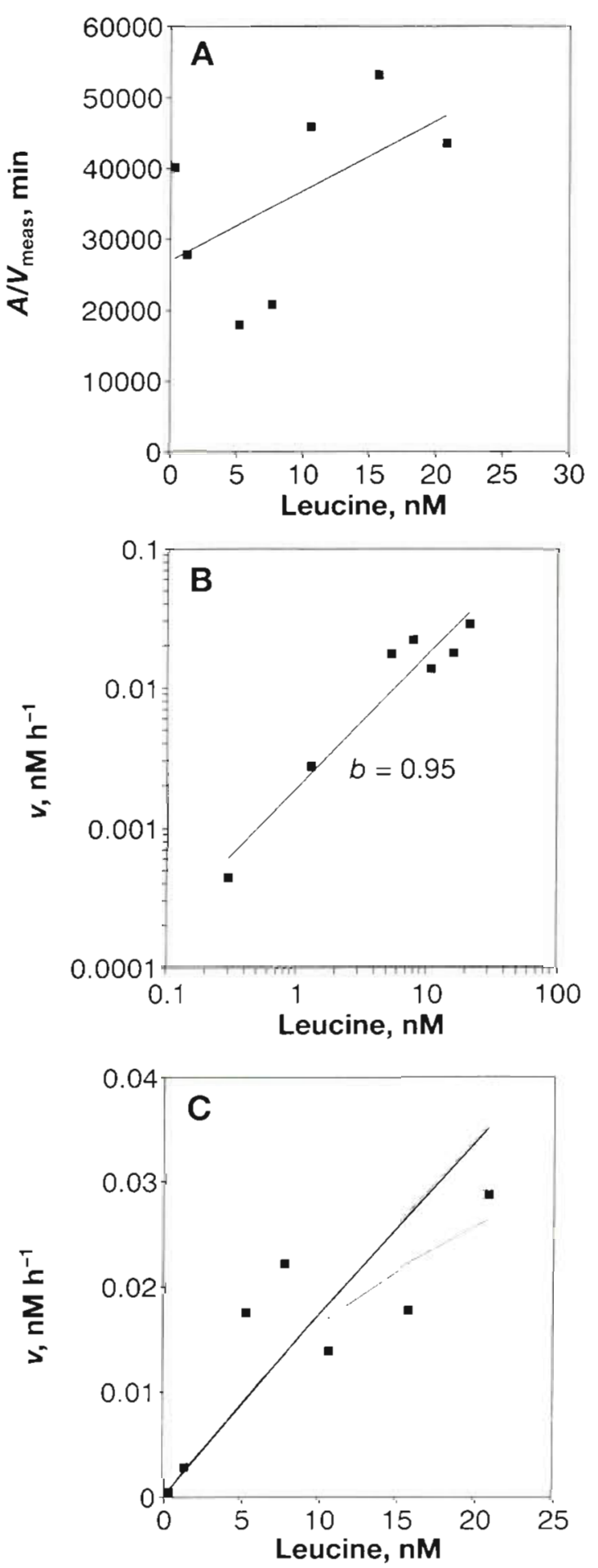

Fig. 8. Leucine uptake by a marine sample filtered through a $1.0 \mu \mathrm{m}$ filter $(10 \mathrm{ml}$ samples incubated $6 \mathrm{~min}$ ) over a concentration range ( 0 to $20 \mathrm{nM}$ ) typically used in protein incorporation studies: (A) data analyzed on a Wright-Hobbie plot produce insignificant regression parameters $\left(\mathrm{r}^{2}=0.30, V_{\max }=\right.$ $0.001 \mathrm{nM} \mathrm{min}-1, K=27 \mathrm{nM}$ ); (B) same data fitted with the diffusion model $\left(\mathrm{r}^{2}=0.92, k=0.0195, b=0.95\right)$; (C) both results shown on linear axes assuming $S=0$ (一: diffusion model; : saturation model)

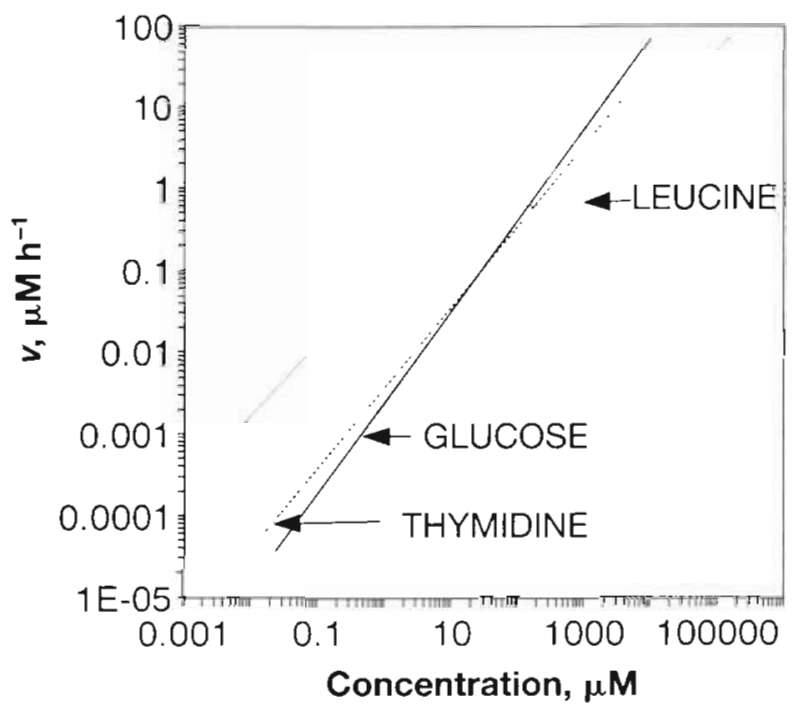

Fig. 9. Comparison of calculated uptake and incorporation rates of glucose (-), leucine $(\cdots)$ and thymidine (-.) using regression lines from Figs. 3, 5 \& 7

According to a physical model of transport through a permeable membrane, the observed rate of transport through the membrane $R$ is:

$$
R=k_{\mathrm{p}} a\left(C-C_{1}\right)
$$

where $k_{p}=$ permeability constant of the membrane; $a=$ surface area; $C=$ bulk substrate concentration, and $C_{\mathrm{i}}=$ concentration in the cell interior. The permeability of the outer membrane of a microorganism may be variable for different microorganisms and different compounds. Since $k_{p}$ is defined as a constant in Eq. (10), variability in $k_{p}$ for different species would make it appear for mixed cultures that there was a non-linear response of uptake with concentration.

In order for transport across a membrane to increase with the external, or bulk, substrate concentration, the concentration of substrate within the cell must always be less than the bulk concentration. If substrate is rapidly removed or transformed in the cell, then $C_{\mathrm{i}} \ll C$ and the rate is first order with concentration. However, if substrate were to accumulate in the cell so that $C_{1}$ approached $C_{1}$ uptake would decrease producing a result that would appear just like saturation kinetics. This situation would be more complex in mixed culture. Different internal pool concentrations of a compound in different strains of microorganisms could produce non-linear uptake kinetics depending on the percent of the population unable to alter $C_{1}$ relative to external substrate concentrations. The response of different strains to variable external concentrations of substrate during incubations could explain why saturation kinetics could be observed in many samples even if only diffusive transport was important. 
The actual intracellular concentrations of glucose, leucine and thymidine were not investigated here, although other studies indicate there are differences in the concentrations of these chemicals after transport into the cell. Glucose can be actively transported and immediately phosphorylated inside the cell via the phosphoenopyruvate phosphotransferase system or by other phosphorylation reactions (Eagon \& Phibbs 1971). This phosphorylation step reduces the concentration of glucose within the cell, maintaining a concentration gradient across the membrane. Similarly, thymidine is also phosphorylated to thymidine monophosphate (Hollibaugh 1988), reducing the concentration of thymidine within the cell and maintaining the gradient. It is not known, however, if a similar situation exists for leucine. Simon \& Azam (1989) found leucine concentrations within marine bacteria were ca $1 \mathrm{mM}$ in the presence of naturally ocurring nanomolar concentrations of leucine (Simon \& Azam 1989). The presence of relatively high concentrations of leucine in the cell would make leucine uptake much different from glucose and thymidine uptake.

The relative rates of thymidine and leucine incorporation are compared with glucose uptake in Fig. 9, using the regression results for the pure culture from Figs. 3, 5 \& 7. Thymidine incorporation and glucose uptake were linear and similar in magnitude over the whole concentration range examined, but leucine incorporation reached a plateau from 0.1 to $1 \mathrm{mM}$. Above $1 \mathrm{mM}$, leucine incorporation again increased linearly with concentration. We propose that thymidine and glucose uptake continuously increased with concentration due to the phosphorylation of these compounds. This phosphorylation step 'removed' these 2 compounds from the internal pool of the cells allowing uptake and incorporation to increase with increased substrate concentrations. Leucine uptake, however, did not continuously increase because at concentrations less than $1 \mathrm{mM}$ the concentration gradient was not in the direction of leucine transport into the cell. Increased uptake with concentrations lower than the internal concentrations suggests that leucine must be actively transported into the cell at leucine concentrations less than the internal pool concentration. Active transport systems for leucine (leucine porters) have been found for Gram-negative bacteria, the most common type of aquatic bacteria (Nikaido \& Vaara 1987).

Basic differences between glucose and leucine uptake have also been observed on the effect of fluid mechanical environment on microbial uptake kinetics (Logan \& Dettmer 1990, Confer \& Logan 1991, Logan \& Kirchman 1991). It was found that leucine uptake could be increased by advective flow past the cell and by fluid shear at low concentrations (ca $1 \mathrm{nM}$ ) of leucine. However, at higher leucine concentrations (ca
$10 \mathrm{nM}$ ), fluid motion had no effect on uptake. The lack of an effect of fluid motion on uptake was explained by saturation of enzymes at the cell surface involved in active transport into the cell. However, at all concentrations of glucose examined, fluid motion had no effect on glucose uptake.

In order for fluid motion to increase uptake, concentration gradients must exist at the cell surface. If there is only passive transport or if the rate of active transport is very low, gradients will not develop around the cell exterior. Thus, fluid motion would not affect uptake since there were no gradients to be reduced by shear or flow past the cell surface.

Non-saturable transport as a result of diffusive transport into the cell has important implications for bacterial production studies using radiolabeled thymidine and leucine. A critical assumption in the technique is that the rate of incorporation is independent of concentrations used to saturate uptake (Kaplan et al. 1992). If uptake cannot be saturated, as has been shown here, then conversion factors will be a function of the concentration of thymidine used in the concentration region where diffusive transport dominates. Moreover, if the diffusive flux through the membrane is important, then the chemical flux into the cell may be a function of environmental conditions.

A lack of saturable kinetics for thymidine has been noted by others. Hollibaugh (1988) found that while thymidine incorporation into DNA and into RNA saturated at 8 to $16 \mathrm{nM}$, incorporation into proteins increased continuously to the highest thymidine concentrations used (256 $\mathrm{nM}$ ). No incorporation maximum was observed for thymidine incorporation by bacterial assemblages from Lake Lötsjon, Sweden (a mesotrophic lake), and incorporation was linear with concentrations in the range of 5 to $50 \mathrm{nM}$ (Bell 1990). Kaplan et al. (1992) also found for stream bed sediments that there was a linear relationship between thymidine concentration and both uptake and incorporation at concentrations that ranged over 3 orders of magnitude $(0.031$ to $53 \mu \mathrm{M})$.

The lack of saturation kinetics for whole cells over large ranges in substrate concentrations is not meant as an argument against the existence of active or facilitated transport over all ranges in substrate concentrations. There is evidence that certain bacteria possess specific pathways to transport many chemicals, such as leucine and glucose (Eagon \& Phibbs 1971, Stryer 1981, Nikaido \& Vaara 1987), into the cell. However, we do question whether most bacteria in natural (or laboratory) conditions possess these operating enzyme systems over the concentration range implied by experiments showing 'multiphasic kinetics'. It is suggested that in future experiments the existence or absence of saturable kinetics could be explored better by using a wider range of added substrates concentrations. 
Acknowledgements. We thank D. L. Kirchman for many long and stimulating conversations on bacterial uptake kinetics, comments by $M$. Simon, and the assistance of $D$. Wilkinson with marine samples. Support for this project was provided by ONR Grants NOOO14-87-K-0108 and NOOO14-91-J-1249, and NSF Grant BCS-8912893.

\section{LITERATURE CITED}

Azam, F., Hodson, R. E. (1981). Multiphasic kinetics for D-glucose uptake by assemblages of natural marine bacteria. Mar. Ecol. Prog. Ser. 6: 213-222

Bailey, J. E., Ollis, D. F. (1977). Biochemical engineering fundamentals. McGraw-Hill, New York

Bell, R. T. (1990). An explanation for the variability in the conversion factor deriving bacterial cell production from incorporation of $\left[{ }^{3} \mathrm{H}\right]$ thymidine. Limnol. Oceanogr. 35: $910-915$

Confer, D. R., Logan, B. E. (1991). Increased bacterial uptake of macromolecular substrates with fluid shear. Appl. environ. Microbiol. 57: 3093-3100

Eagon, R. G., Phibbs, P. V. (1971). Kinetics of transport of glucose, fructose and mannitol by Pseudomonas aeruginosa. Can. J. Biochem. 49: 1031-1041

Fleury, R. C. (1993). Thymidine and leucine incorporation as indicators of bacterial activity and the uptake of glucose M.Sc. thesis, University of Arizona, Tucson

Fuhrman, J. A., Azam, F. (1982). Thymidine incorporation as a measure of heterotrophic bacterioplankton production in marine surface waters: evaluations and field results. Mar. Biol. 66: 109-120

Fuhrman, J. A., Ferguson, R. L. (1986). Nanomolar concentrations and rapid turnover of dissolved free amino acids in seawater: agreement between chemical and microbiological measurements. Mar. Ecol. Prog. Ser. 33 $237-242$

Hobbie, J. E., Daley, R. J., Jasper, S. (1977). Use of nuclepore filters for counting bacteria by fluorescence microscopy Appl. environ. Microbiol. 33: 1225-1228

Hollibaugh, J. T (1988). Limitations of the $\left[{ }^{3} \mathrm{H}\right]$ thymidine method for estimating bacterial productivity due to thymidine metabolism. Mar. Ecol. Prog. Ser. 43: 19-30

Jørgensen, N. O. G., Sondergaard, M. (1984). Are dissolved free amino acids free? Microb. Ecol. 10: 301-316

This article was submitted to the editor
Kaplan, L. A., Bott, T. L., Biolicku, J. K. (1992). Assessment of $\left[{ }^{3} \mathrm{H}\right]$ thymidine incorporation into DNA as a method to determine bacterial productivity in stream bed sediments. Appl. environ. Microbiol. 58: 3614-3621

Kirchman, D. L., K'Nees, E., Hodson, R. (1985). Leucine incorporation and its potential as a measure of protein synthesis by bacteria in natural aquatic systems. Appl. environ. Microbiol. 49: 599-607

Kirchman, D. L., Murraz, R. E., Hodson, R. E. (1986). Rates of DNA and protein synthesis by heterotrophic bacteria in aquatic environments: a comparison between the thymidine and leucine approaches. Proc. int. Symp. microbial Ecol. 4: 631-637

Lindroth, P., Mopper, K. (1979). High performance liquid chromatographic determination of subpicomole amounts of amino acids by pre-column fluorescence derivitization with o-phthaldialdehyde. Analyt. Chem. 51: 1667-1674

Logan, B. E., Dettmer, J. W. (1990). Increased mass transfer to microorganisms with fluid motion. Biotechnol. Bioeng. 35: $1135-1144$

Logan, B. E., Kirchman, D. L. (1991). Increased uptake of dissolved organics by marine bacteria as a function of fluid motion. Mar. Biol. 111 175-181

Mopper, K., Schultz, C. A., Chevolot, L., Germain, C., Revuelta, R., Dawson, R. (1992). Determination of sugars in unconcentrated seawater and other natural waters by liquid chromatography and pulsed amperometric detection. Environ. Sci. Technol. 26: 133-138

Nikaido, H., Vaara, M. (1987). Outer membrane. In: Neidhardt, F. C. (ed.) Escherichia coli and Salmonella typhimurium, Vol. 1. American Society for Microbiology, Washington, DC, p. 7-22

Nissen, H., Nissen, P., Azam, F. (1984). Multiphasic uptake of D-glucose by an oligotrophic marine bacterium. Mar. Ecol. Prog. Ser. 16: 155-160

Simon, M., Azam, F. (1989). Protein content and protein synthesis rates of planktonic marine bacteria. Mar. Ecol. Prog. Ser. 51: 201-213

Stryer, L. (1981). Biochemistry, 2nd edn. W. H. Freeman \& Co., San Francisco

Wetzel, R. G. (1983). Limnology, 2nd edn. Saunders College Publ., Philadelphia

Wright, R. T., Hobbie, J. E. (1966). Use of glucose and acetate by bacteria and algae in aquatic ecosystems. Ecology 47 : $447-464$

Manuscript first received: April 18, 1993

Revised version accepted: August 11, 1993 